\title{
Pilot test of an online training module on near-infrared spectroscopy monitoring for the randomised clinical trial SafeBoosC-III
}

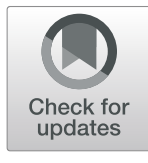

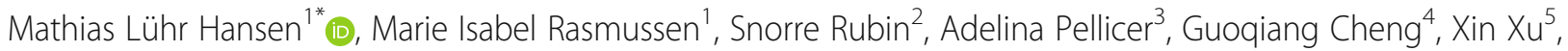
Yin Zhaoging ${ }^{6}$, Vibeke Zoffmann ${ }^{7}$ and Gorm Greisen ${ }^{1}$

\begin{abstract}
Background: SafeBoosC-III is an international randomised clinical trial to evaluate the effect of treatment of extremely preterm infants during the first 3 days of life based on cerebral near-infrared spectroscopy (NIRS) monitoring versus treatment and monitoring as usual. To ensure high quality of the trial intervention as well as of patient care, we have developed a multilingual web-based training program to train relevant staff and test their competence. As we enter an under-explored area of e-learning, we have conducted a pilot study on the first of the five modules comprising the web-based training program to test the feasibility of developing such a program for an international trial with limited resources.
\end{abstract}

Methods: The module in this study focuses on the principles and practice of NIRS monitoring. The pedagogical idea was to integrate training and certification. One-hundred doctors and nurses from five Neonatal Intensive Care Units across China, Spain and Denmark were invited to participate in the pilot study. Upon completion of the NIRS module, participants were invited to evaluate their experience by completing an online survey. Data from closedended questions were analysed using descriptive statistics while data from open-ended questions underwent thematic analysis.

Results: In total, 81 of 100 invited staff members entered the training module and completed the online survey. The median time and the number of questions to pass the module was 15 minutes and seven questions, respectively. Most staff found the academic level of the learning material and quiz appropriate $(85 \%$ and $93 \%$ of all staff members, respectively), as well as agreeing that the module was relevant to prepare them to 'use the NIRS device' (90\%). Thematic analysis revealed issues such as a discrepancy between learning material and quiz questions, lack of clarity, and technical issues.

Conclusion: We provide evidence of the feasibility of developing a multilingual web-based training program for an international trial, despite challenges such as low budget, language barriers and possibly differences in the clinical training of staff. Exploring the integration of training and certification for international trials, the positive results of this study motivate further developments.

(Continued on next page)

* Correspondence: mathias.luhr.hansen@gmail.com

'Department of Neonatology, Rigshospitalet, Blegdamsvej 9, 2100 Copenhagen, Denmark

Full list of author information is available at the end of the article

C The Author(s). 2020 Open Access This article is licensed under a Creative Commons Attribution 4.0 International License, which permits use, sharing, adaptation, distribution and reproduction in any medium or format, as long as you give appropriate credit to the original author(s) and the source, provide a link to the Creative Commons licence, and indicate if changes were made. The images or other third party material in this article are included in the article's Creative Commons licence, unless indicated otherwise in a credit line to the material. If material is not included in the article's Creative Commons licence and your intended use is not permitted by statutory regulation or exceeds the permitted use, you will need to obtain permission directly from the copyright holder. To view a copy of this licence, visit http://creativecommons.org/licenses/by/4.0/. The Creative Commons Public Domain Dedication waiver (http://creativecommons.org/publicdomain/zero/1.0/) applies to the data made available in this article, unless otherwise stated in a credit line to the data. 
(Continued from previous page)

Trial registration: ClinicalTrial.gov, NCT03770741. Registered 10 December 2018.

Keywords: SafeBoosC, Randomised clinical trial, Randomized clinical trial, RCT, Extremely preterm, Near-infrared spectroscopy, NIRS, Online training, Web-based training, E-learning

\section{Background}

Randomised clinical trials are considered the highest level of evidence when evaluating the effects of a clinical intervention [1]. It is therefore essential that the methodological quality is high. Furthermore, since randomised clinical trials are conducted on human subjects [2], the safety and well-being of participants are of crucial importance. Good Clinical Practice (GCP) is an international standard for designing, conducting, recording and reporting clinical trials involving human subjects, with the purpose of ensuring the safety and wellbeing of trial subjects as well as high scientific quality [3]. A core principle in GCP is that staff members involved in the trial "should be qualified by education, training and experience to perform his or her respective $\operatorname{task}(\mathrm{s})$ " [3]. One way to ensure this is by training the clinical staff [4]. Despite evidence suggesting that training staff members in trial-related tasks has a positive effect on the trial's results [5], the training process is rarely reported [6]. Furthermore, recommendations for specific training requirements for clinical trials are not defined in the standards on GCP by the International Committee on Harmonisation.

To recruit enough participants, large-scale clinical trials often include many centres across multiple countries. This poses the problem of training staff since on-site training is expensive, time-demanding and difficult to standardise. A way to bypass this issue, while preserving the quality of training, is by using e-learning. E-learning is a broad concept describing education facilitated through electronic systems, such as computers or mobile devices [7], and, as such, can be used to ensure standardised delivery of subject matter [8].

E-learning has already proven to be a valuable asset when increasing the competencies of health professionals, in both industrial and developing countries [8-13], and has been proliferating until now with the purpose of medical education at universities, as a counteraction to traditional classroom teachings [14]. It has proven to be a useful tool when harmonizing teachings that are aimed worldwide, across different languages and clinical settings, and has been used with great progress in resource-constrained countries [15].

A recent Cochrane review of e-learning, which it defined as any educational intervention mediated electronically via the internet, was found non-inferior to traditional classroom teaching $[8,16]$, and in the few published reports on e- learning as preparation for clinical trials, it has been implemented with success [4].

A consensus on a clear definition of e-learning does not exist. Therefore, multiple terms are used as synonyms for e-learning, including internet-based learning, web-based learning and training, computer-assisted instructions and computer-based learning and training $[8,17-19]$. For the purpose of this study, we will use the term 'web-based training' (see the 'Web-based training and certification program' section).

\section{The SafeBoosC-III trial}

SafeBoosC-III is a randomised clinical trial investigating the benefits and harms of treatment based on cerebral near-infrared spectroscopy (NIRS). The hypothesis is that treatment based on NIRS monitoring during the first $72 \mathrm{~h}$ of life of extremely preterm infants will result in a reduction of severe brain injury and death at 36 weeks postmenstrual age. Sixteen-hundred infants born with a gestational age below 28 weeks and admitted to more than 50 neonatal intensive care units across 20 different countries will be randomised. Infants in the experimental group will receive treatment guided by cerebral NIRS monitoring during the first $72 \mathrm{~h}$ of life, while infants in the control group will receive treatment and monitoring as usual. The protocol of the SafeBoosC-III trial is registered at www.ClinicalTrials.gov, NCT 03770741 (07.12.2018).

When working at a clinical department, it is often expected that you are familiar with routine practices. If you are not, learning will often happen through supervision by more experienced colleagues familiar with the interventions. However, when an intervention trial is rolled out in a clinical department, only a few staff members may be familiar with the intervention. Thus, training in trial-related procedures is necessary, not only for the safety of trial participants but also to give a relevant and practical estimate on the effect of the intervention in routine practice. This is done through a pragmatic trial such as SafeBooSC-III, where the purpose is to test the effect of a given intervention in a real-world setting [20], i.e. what effect can be expected by implementing a specific intervention in a broad patient group, in a large number of departments. Therefore, in order to estimate the potential effect of implementing an intervention in routine practice, staff on-site should be trained in the intervention before the trial takes off $[3,20]$. However, if 
the trial ought to reflect how the intervention works in a real-world scenario, the level and intensity of staff training should reflect this, meaning that you do not want to train your staff members to an expert level prior to trial initiation since this does not reflect a 'real-world' scenario and you will not thus get generalizable trial results. To provide a practically realistic level of introduction and training for the SafeBoosC-III trial, we have developed a multilingual online training program to train relevant staff and test their competence.

As we enter an under-explored area of e-learning, we have conducted a pilot study on the first of the five modules comprising the web-based training program to test the feasibility of developing such a program on limited resources for an international trial. We expected that results from this pilot study could be used to enhance and support further development of the web-based training and certification program for SafeBoosC-III, and possibly encourage the use of e-learning when implementing future international clinical trials.

\section{Methods}

Fifty nurses and 50 doctors from a total of five neonatal intensive care units across China, Denmark and Spain were invited to participate in the pilot study. In order to ensure that the e-learning tool was appropriate for staff of all levels of experience, the responsible investigators within each of the five participating neonatal intensive care units (AP, GC, MLH, XX, ZY) invited staff members with and without prior NIRS experience to participate. All neonatal intensive care units participating in this pilot study are planning to participate in SafeBoosCIII, and all participating staff members are expected to care for babies enrolled in SafeBoosC-III.

Participants were asked to 1) complete the web-based training module on NIRS monitoring and 2) evaluate it through an online survey.

\section{Web-based training and certification program}

The training module is part of a complete web-based training and certification program for the SafeBoosC-III trial, which will be offered to all doctors and nurses involved in the care of trial participants. It consists of five separate modules covering 1) introduction to SafeBoosCIII and the protocol, 2) cerebral NIRS monitoring, 3) SafeBoosC-III treatment guideline, 4) cranial ultrasound imaging and diagnosing of brain injury, and 5) GCP monitoring in SafeBoosC-III. All modules are designed as integrated training and certification modules, with each module consisting of a) learning material and b) a quiz. With the exception of the introduction module, all modules are built over a simplified adaptive framework, meaning that you are led directly to the quiz and will only be prompted to visit the learning materials if your answers to questions are wrong. If you answer all questions correctly, you have shown mastery of the subject matter and will be certified directly. As such the quiz is designed to recognize prior learning, as correct answers will get participants through the modules faster. For less experienced users, the option is given for the user to bypass the quiz and go directly to the learning materials first (Fig. 1).

The content for all modules was developed with the same approach: Initially, a narrative text covering all essential knowledge on the subject was drafted. Based on the narrative, a number of learning objectives were developed, all clearly described according to Bloom's Taxonomy's cognitive domain [21] to specify which degree of mastery the user should show. The narrative was also used to write the learning material for each module. Next, two to four questions related to each learning objective were developed, thereby representing a pool of questions used to build the quiz. The questions strive to be as relevant as possible and were therefore formulated in a case-like manner, with a short description of a clinical situation given for each question, followed by a varying number of response options. Cases reflect clinical situations that could happen during the conduct of SafeBoosC-III. Often, there are several correct response options constituting the format of multiple-choice questions with several-of-many answers. To pass a question, all the correct answers and only correct answers must be ticked (Fig. 2a). Participants complete a module when they have answered one question per learning objective correctly. We could have chosen to require two (or three) correct answers per learning objective, but this would have inflated the volume of questions-and hence the costs-as well as the time to be used by participants. They will be exposed to new questions or re-exposed to questions they have already met from the quiz-pool on a continuous basis until the above criterion is met. Questions in the learning objectives that at any given time are not yet passed are presented in random order. This is done to reduce the risk that participants adopt a fast game, like a 'trial and error' strategy, rather than learning and understanding.

The teaching methodology is case-based and uses immediate detailed feedback, which means that participants will be presented with explanations for right and wrong answers as they go (Fig. 2b). This method has been shown to increase student performance in previous online medical education programs [22].

The complete web-based training and certification program will be hosted in a Moodle virtual learning environment (Moodle Pty Ltd, West Perth, WA, Australia), a commonly used shareware software within online medical training [10, 11, 23]. However, Moodle was not used as the platform for this pilot project due to restricted time. Instead, a direct link with immediate access to the module was used. The platform used in this pilot study was the 


\section{NIRS Monitoring}

\section{Dear Unknown}

Welcome to the learning material on near-infrared spectroscopy (NIRS) monitoring. On the following pages you will be introduced to the most important aspects of NIRS monitoring in newborn babies. Reading this will help you get through the quiz faster. However, all answers to quiz questions cannot be found directly in this learning material - in some cases, you will also have to use your own clinical skills, in order to solve them.

Within this learning material, we will present to you a case, similar to those that you will meet during the quiz.

The learning material is rather short and dense. This is done in order to minimize reading time. Therefore, please read the material carefully.

You can open the short learning material here. You can go back to the learning material at any time.

\section{Go to ouiz}

Fig. 1 On the opening page, the participant will see a short introduction text and the possibility to 1) open the introduction material ('here' in blue text) or 2) go to the quiz (in the middle of the lower blue bar)

Capital Region of Denmark's primary platform for elearning, providing almost 400 different training programs for 40,000 staff members (kursusportalen.plan2learn.dk).

\section{Training module on NIRS}

The module on NIRS monitoring which was piloted in this study focuses on the principles of measuring cerebral oxygenation by NIRS, basic device operation, application and fixation of the sensor to the head of the infant, care of sensor and repositioning, the risk of skin marks, interpretation of measured values and the concept of venous-weighted tissue blood oxygenation. It consists of four learning objectives and 11 questions (Table 1). SHS and GG [24-28] took the lead in writing the learning material as well as questions for the quiz. MLH also participated in this process. MIR and SR programmed the training module in the interactive elearning software Articulate Storyline (Articulate, New York, NY, US) and provided a direct URL link for participants to use. SR is an employee of the Copenhagen University Hospital e-learning section and is mainly responsible for programming all modules for the web-based training and certification program.

Since SafeBoosC-III is a multinational trial, language barriers can pose as a challenge because the content of the web-based training program must be translated to all the languages and still hold an academic level which meets clinical standards without the translation process being too complex. Therefore, in order to test the feasibility of translating the content of the web-based training program and train staff members in local languages, the original English version was translated into both Spanish and Chinese. The translation was done locally by the national coordinators AP in Spain and GC in China, who conducted manual translation of the material from English to Spanish and Chinese, respectively. In China, GC conducted the translation with the aid of the online translation tool 'youdao.com' whenever he was in doubt of the correct translation. Due to limited resources, the quality and precision of the translations were not evaluated by external linguistic experts and no back-translation and comparison with the originals were conducted. Danish participants were trained in the English module and Chinese and Spanish participants in the Chinese and Spanish modules, respectively.

\section{Survey}

Upon completion of the NIRS module, participants were asked to evaluate their experience by completing an online survey. For Spanish and Danish participants, the online survey was hosted in Google Analytics (Google LLC, Mountain View, CA, USA), but since Google is blocked in China, a Chinese survey program, Wenjuan (Shanghai 
a)

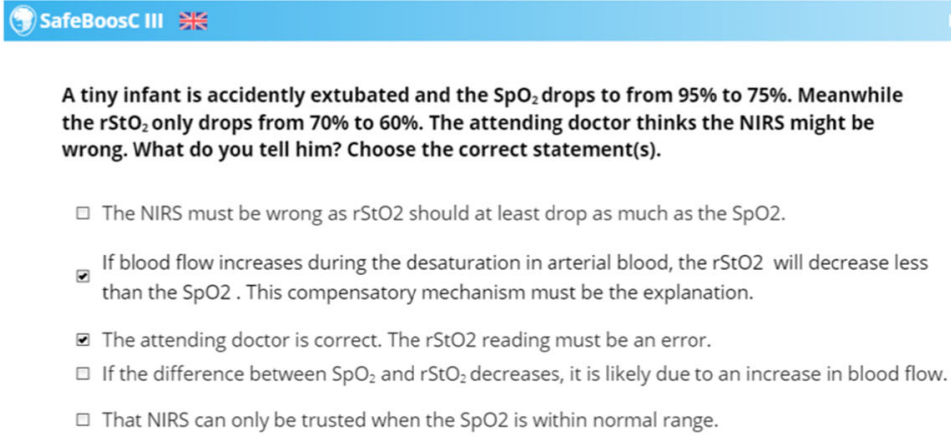

b)

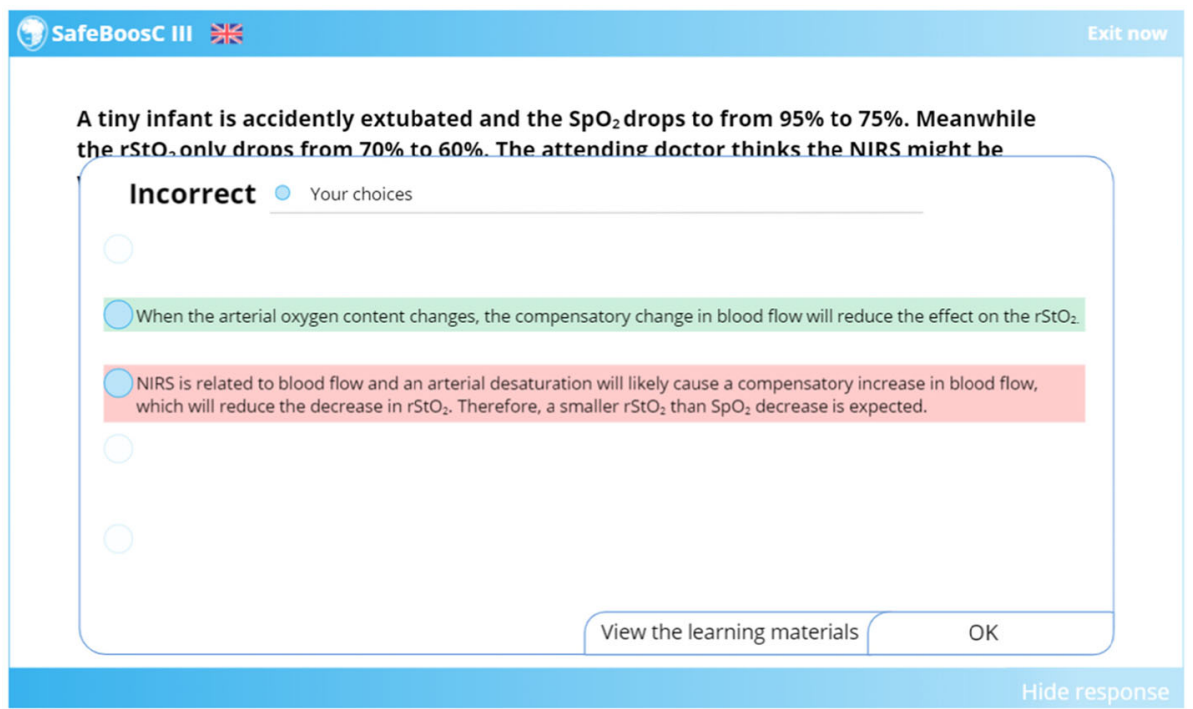

Fig. 2 Example of a question from the NIRS module. a The case-text describing the clinical setting and the five answer possibilities; options two and three have been chosen. $\mathbf{b}$ Explanations to answers are presented; option two was correct, while option 3 was wrong. This means that the question is not passed and the participant will be presented with another question on the same learning objective and have to answer that correctly before completing the quiz

Zhongyan Network, Shanghai, China), was used to host the Chinese survey. Participants completed the survey in local languages. As for the web-based training module, the translation of the survey was done locally by AP and GC. The online survey consisted of 15 closed-ended questions with answers on a three- or four-step Likert scale and seven open-ended questions with free-text answers. The structure and content of the closed-ended questions are based on Wang's principles for e-learner satisfaction [29]. Open-ended questions were added to gain a deeper and more complex understanding of participants' experiences and to clarify potential room for improvement. The survey covered the following themes: 1) performance, 2) learning material, 3) quiz material, 4) interface, and 5) preparation to use NIRS monitoring in a clinical context. MIR and MLH developed the online survey.

\section{Data analysis}

Quantitative data from closed-ended questions were analysed using basic descriptive statistics. Analysis of answers to the open-ended questions followed the principles of thematic analysis as described by Braun and Clarke [30]. With an inductive and data-driven approach, an iterative six-step analysis was conducted to 
Table 1 Learning objectives and questions for the training module on NIRS monitoring

\begin{tabular}{ll}
\hline Learning objective & Question \\
\hline Point out differences between & A father of a very preterm infant \\
NIRS tissue oxygenation $\left(\mathrm{rStO}_{2}\right)$ & $\begin{array}{l}\text { asks why the cerebral } \mathrm{rStO}_{2} \text { is } 65 \\
\text { and pulse oximetry }\end{array}$ \\
$\begin{array}{l}\text { when the } \mathrm{SpO}_{2} \text { is } 94 \text {. What do you } \\
\text { tell him? }\end{array}$
\end{tabular}
tell him?

A baby is pale and mottled and you suspect circulatory failure due to septic shock. You have a hard time getting a signal from the pulse oximeter, but the NIRS gives readings with no apparent problems. Choose the correct statement(s)

Recognise the consequences of $\mathrm{rStO} 2$ being a direct measure of cerebral oxygen consumption/ supply balance and indirect measure of cardiac output

Know the elements in starting up NIRS monitoring and interpret values during monitoring

Know the side effects of NIRS monitoring
Table 1 Learning objectives and questions for the training module on NIRS monitoring (Continued)

\begin{tabular}{ll}
\hline Learning objective & Question \\
\hline Tou take over the care of a baby in \\
experimental group. Gestational \\
age is 24 weeks and he is \\
mechanically ventilated with high \\
pressures and on high dose \\
pressor (dopamine 15 microgram/ \\
kg/min) and yet the mean arterial \\
blood pressure is only 24 mmHg. \\
The situation, however, has been \\
stable for the last $12 \mathrm{~h}$. The \\
cerebral oximeter seems to work \\
well and the rStO2 is $65 \%$ (the \\
hypoxic threshold of your oximeter \\
is 58\%). Choose what you will do? \\
A mother notices a minor mark on \\
the skin after you have moved the \\
pulse oximeter sensor to another \\
position. She is now concerned \\
about the NIRS sensor as well. \\
What answers can you give her? \\
\hline
\end{tabular}

identify themes across the entire data set [30]. Initially, answers were systematically reviewed and coded. In total, 111 answers were coded into 70 codes, which subsequently were narrowed into 64 codes, based on their similarities (Table 2).

All 64 codes were collated and grouped into seven candidate themes. In order to get a better overview of data, candidate themes were illustrated in mind maps and reviewed in relation to 1) their specific data extracts and 2) across the entire data set. In this process, themes that covered similar aspects were merged, and irrelevant themes were either deleted or re-assembled, which resulted in four final themes.

\section{Ethics approval and consent to participate}

According to Danish, Chinese and Spanish laws, survey studies are not considered biomedical research and ethics approval was not therefore required to conduct this study. An information sheet written by MLH and GG explaining the purpose of the pilot project, that no personal data were collected and that all survey answers were recorded and analysed anonymously was distributed to the responsible investigators in each of the five participating neonatal intensive care units (AP, GC, $\mathrm{MLH}, \mathrm{XX}$ and YZ). The five investigators invited relevant staff members to participate in the pilot study and, based on the information sheet, informed them of the study and data handling. All staff members had the possibility to ask the responsible investigators questions on the study and the possibility to decline participation in this pilot study. Since no personal identifiers were registered on participants, it was impossible to identify the identity of individual survey responders and thus 
Table 2 Examples of data extract coding. Narrative to the left and codes to the right

\begin{tabular}{ll}
\hline $\begin{array}{l}\text { Fine academic level, but some } \\
\text { of the questions did not match } \\
\text { the introduction material, which }\end{array}$ & $\begin{array}{l}\text { 1. Discrepancy between } \\
\text { introduction material and quiz }\end{array}$ \\
$\begin{array}{l}\text { 2. Frustrations a shame and frustrating } \\
\text { (in relation to agreeing/strongly }\end{array}$ & $\begin{array}{l}\text { 3. Academic level appropriate } \\
\text { agree that the academic level }\end{array}$ \\
$\begin{array}{ll}\text { of the quiz was appropriate) } \\
\text { to answer quiz questions }\end{array}$ \\
$\begin{array}{ll}\text { The question is not related to } \\
\text { the learning material. The language } \\
\text { is not enough concise and clear }\end{array}$ & $\begin{array}{l}\text { 1. Discrepancy between the } \\
\text { introduction material and quiz }\end{array}$ \\
\hline
\end{tabular}

withdrawal of data was not possible. This design was chosen to protect the participants against employers and responsible investigators back-tracking the performance or survey completion of individuals.

\section{Results}

In total, 81 of 100 invited staff members (81\%) entered the training module and completed the online survey. Fifty (62\%), 16 (20\%) and 15 (18\%) staff members responded from China, Spain and Denmark, respectively. Of the 81 responders, 41 were doctors (51\%) and 40 were nurses (49\%). Previous experience with NIRS monitoring was reported by 46 of the 81 responders (57\%), including 26 doctors (57\%) and 20 nurses (43\%) (Table 5). In Denmark, six of the 15 responders had previous experience (40\%), in China 25 of 50 (50\%), and in Spain 15 of 16 (94\%).

\section{Closed-ended questions Performance}

Overall, responders spent a median time of $15 \mathrm{~min}$ (range 1 to $420 \mathrm{~min}$ ) and a median number of seven questions (range 4 to 50 questions) to complete the NIRS module. Spanish responders were faster than both Danish and Chinese (median 10, 14 and $20 \mathrm{~min}$, respectively) and used fewer questions to pass (median 4, 7 and 8, respectively) (Table 3). Doctors were faster than nurses (median 13.5 versus $20 \mathrm{~min}$ ) and used fewer questions to pass (median 6 versus 9 questions) (Table 4). Responders with NIRS experience were faster than non-experienced (median 13.5 min versus $20 \mathrm{~min}$ ) and spent fewer questions to pass (median 5.5 versus 8 questions) (Table 5).

\section{Learning material}

Overall, 69 of 81 (85\%) responders found the academic level of the learning material appropriate and none found it too easy. Of the 12 responders who found the learning material

Table 3 Time used and number of quiz questions used to complete the module and number of responding participants who answered either 'agree'/'strongly agree' or 'appropriate' to the questions regarding the design of the module (data stratified by country)

\begin{tabular}{|c|c|c|c|c|}
\hline Question & Denmark & Spain & China & Total \\
\hline \multicolumn{5}{|l|}{ Performance } \\
\hline Minutes to complete module, median [range] & $14[7-30](11 / 15)^{c}$ & $10[1-60](13 / 16)^{c}$ & $\begin{array}{l}20[2-420] \\
(46 / 50)^{c}\end{array}$ & $\begin{array}{l}15[1-420] \\
(70 / 81)^{c}\end{array}$ \\
\hline $\begin{array}{l}\text { Number of questions to complete module } \\
\text { median [range] }\end{array}$ & $7[6-20](5 / 15)^{c}$ & $4[4-12](13 / 16)^{c}$ & $8[4-50](43 / 50)^{c}$ & $\begin{array}{l}7[4-50] \\
(61 / 81)^{c}\end{array}$ \\
\hline \multicolumn{5}{|l|}{ Learning material } \\
\hline $\begin{array}{l}\text { Academic level of learning material } \\
\text { appropriate, } n / N(\%)\end{array}$ & 14/15 (93) & 15/16 (94) & $40 / 50(80)$ & $69 / 81(85)$ \\
\hline $\begin{array}{l}\text { Learning material sufficient to complete } \\
\text { quiza }^{\mathrm{n}} \mathrm{n} / \mathrm{N}(\%)\end{array}$ & $3 / 12(25)$ & $13 / 16(81)$ & $39 / 50(78)$ & $55 / 78(70)$ \\
\hline \multicolumn{5}{|l|}{ Quiz } \\
\hline Academic level of quiz appropriate ${ }^{a}, \mathrm{n} / \mathrm{N}(\%)$ & $14 / 15(93)$ & 15/16 (94) & $46 / 50(92)$ & 75/81 (93) \\
\hline $\begin{array}{l}\text { Number of answering possibilities per question } \\
\text { appropriate, } n / N(\%)\end{array}$ & $6 / 15(40)$ & $9 / 16(56)$ & $34 / 50(68)$ & $49 / 81(60)$ \\
\hline Quiz questions clinically relevant and up-to-date ${ }^{a}$ & 13/14 (93) & 15/16 94) & $49 / 50(98)$ & $77 / 80(96)$ \\
\hline \multicolumn{5}{|l|}{ Interface } \\
\hline $\begin{array}{l}\text { The NIRS module was stable and did not } \\
\text { crashb }^{b}, \mathrm{n} / \mathrm{N}(\%)\end{array}$ & $6 / 15(40)$ & $9 / 15(60)$ & $42 / 50(84)$ & $57 / 80(71)$ \\
\hline \multicolumn{5}{|l|}{ Preparation for using NIRS } \\
\hline Relevant to prepare for using the NIRS device ${ }^{a}$ & $13 / 15(87)$ & $12 / 15(80)$ & $47 / 50(94)$ & $72 / 80(90)$ \\
\hline
\end{tabular}

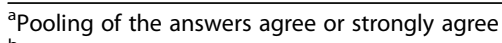

${ }^{b}$ Yes to the statement

${ }^{c}$ Number of responders answering the specific question and the total number of overall responders completing the online survey 
Table 4 Time used and number of quiz questions used to complete the module and number of participants who answered either 'agree'/'strongly agree' or 'appropriate' to the questions regarding the design of the module (data stratified by participants' profession)

\begin{tabular}{|c|c|c|c|}
\hline Question & Doctors & Nurses & Total \\
\hline \multicolumn{4}{|l|}{ Performance } \\
\hline $\begin{array}{l}\text { Minutes to complete } \\
\text { module, median [range] }\end{array}$ & $\begin{array}{l}13.5[2-420] \\
(34 / 41)^{c}\end{array}$ & $\begin{array}{l}20[1-420] \\
(36 / 40)^{c}\end{array}$ & $\begin{array}{l}15[1-420] \\
(70 / 81)^{c}\end{array}$ \\
\hline $\begin{array}{l}\text { Number of questions } \\
\text { to complete module, } \\
\text { median [range] }\end{array}$ & $\begin{array}{l}6[4-30] \\
(28 / 41)^{c}\end{array}$ & $\begin{array}{l}9[4-50] \\
(33 / 40)^{c}\end{array}$ & $\begin{array}{l}7[4-50] \\
(61 / 81)^{c}\end{array}$ \\
\hline \multicolumn{4}{|l|}{ Learning material } \\
\hline $\begin{array}{l}\text { Academic level of } \\
\text { learning material } \\
\text { appropriate, } \mathrm{n} / \mathrm{N}(\%)\end{array}$ & $37 / 41(90)$ & $32 / 40(80)$ & $69 / 81(85)$ \\
\hline $\begin{array}{l}\text { Learning material } \\
\text { sufficient to complete } \\
\text { quiz }^{\mathrm{a}}, \mathrm{n} / \mathrm{N}(\%)\end{array}$ & 28/38 (74) & $27 / 40(68)$ & $55 / 78(70)$ \\
\hline \multicolumn{4}{|l|}{ Quiz } \\
\hline $\begin{array}{l}\text { Academic level of quiz } \\
\text { appropriate }^{\mathrm{a}}, \mathrm{n} / \mathrm{N}(\%)\end{array}$ & 38/41 (93) & $37 / 40(93)$ & 75/81 (93) \\
\hline $\begin{array}{l}\text { Number of answering } \\
\text { possibilities per question } \\
\text { appropriate, } n / N(\%)\end{array}$ & 29/41 (71) & $20 / 40(50)$ & $49 / 81(60)$ \\
\hline $\begin{array}{l}\text { Quiz questions clinically } \\
\text { relevant and up-to-date }\end{array}$ & $39 / 40(98)$ & $38 / 40$ (95) & $77 / 80(96)$ \\
\hline \multicolumn{4}{|l|}{ Interface } \\
\hline $\begin{array}{l}\text { The NIRS module was } \\
\text { stable and did not crash }{ }^{b}, \\
\text { n/N (\%) }\end{array}$ & 29/41 (71) & 28/39 (72) & $57 / 80(71)$ \\
\hline \multicolumn{4}{|l|}{ Preparation for using NIRS } \\
\hline $\begin{array}{l}\text { Relevant to prepare for } \\
\text { using the NIRS device }\end{array}$ & $35 / 40(88)$ & $37 / 40(93)$ & $72 / 80(90)$ \\
\hline
\end{tabular}

${ }^{\text {a }}$ Pooling of the answers agree or strongly agree

${ }^{b}$ Yes to the statement

c Number of responders answering the specific question and the total number of overall responders completing the online survey

too advanced, ten were from China, one was from Denmark and one was from Spain (Table 3). Eight of 40 (20\%) nurses found the learning material too advanced compared to four of 41 (10\%) doctors (Table 4). Additionally, no relevant difference was seen between responders experienced in NIRS monitoring and those with no experience (seven of 46 (15\%) experienced versus five of 35 non-experienced (14\%)) (Table 5). When asked if the introduction material was sufficient to answer quiz questions, 23 of 78 (29\%) responders disagreed or strongly disagreed, nine from Denmark, 11 from China and three from Spain (Table 3). More nurses (13 of 41 (32\%)) than doctors (10 of 38 (26\%)) disagreed or strongly disagreed with this statement (Table 4). Amongst those with NIRS experience, 12 of 44 (27\%) disagreed or strongly disagreed compared to 11 of 34 (32\%) responders with no previous experience (Table 5).
Table $\mathbf{5}$ Time used and number of quiz questions used to complete the module and number of participants who answered either 'agree'/'strongly agree' or 'appropriate' to the questions regarding the design of the module (data stratified by participants' previous experience with NIRS monitoring)

\begin{tabular}{|c|c|c|c|}
\hline Question & Experience & $\begin{array}{l}\text { No } \\
\text { experience }\end{array}$ & Total \\
\hline \multicolumn{4}{|l|}{ Performance } \\
\hline $\begin{array}{l}\text { Minutes to complete } \\
\text { module, median } \\
\text { [range] }(n / N)\end{array}$ & $\begin{array}{l}13.5[1-420] \\
(40 / 46)^{c}\end{array}$ & $\begin{array}{l}20[4-420] \\
(30 / 35)^{c}\end{array}$ & $\begin{array}{l}15[1-420] \\
(70 / 81)^{c}\end{array}$ \\
\hline $\begin{array}{l}\text { Number of questions } \\
\text { to complete module, } \\
\text { median [range] (n/N) }\end{array}$ & $\begin{array}{l}5.5[4-20] \\
(36 / 46)^{c}\end{array}$ & $\begin{array}{l}8[4-50](25 / \\
35)^{c}\end{array}$ & $\begin{array}{l}7[4-50] \\
(61 / 81)^{c}\end{array}$ \\
\hline \multicolumn{4}{|l|}{ Learning material } \\
\hline $\begin{array}{l}\text { Academic level of } \\
\text { learning material } \\
\text { appropriate, n/N (\%) }\end{array}$ & $39 / 46(85)$ & 30/35 (86) & 69/81 (85) \\
\hline $\begin{array}{l}\text { Learning material } \\
\text { sufficient to complete } \\
\text { quiz }^{\mathrm{a}}, \mathrm{n} / \mathrm{N}(\%)\end{array}$ & $32 / 44(73)$ & 23/34 (68) & $55 / 78(70)$ \\
\hline \multicolumn{4}{|l|}{ Quiz } \\
\hline $\begin{array}{l}\text { Academic level of quiz } \\
\text { appropriate }^{a}, \mathrm{n} / \mathrm{N}(\%)\end{array}$ & $41 / 46(89)$ & $34 / 35(97)$ & 75/81 (93) \\
\hline $\begin{array}{l}\text { Number of answering } \\
\text { possibilities per } \\
\text { question appropriate, } \\
\mathrm{n} / \mathrm{N}(\%)\end{array}$ & 27/46 (59) & $22 / 35(63)$ & $49 / 81(60)$ \\
\hline $\begin{array}{l}\text { Quiz questions clinically } \\
\text { relevant and up-to-date }\end{array}$ & 43/46 (93) & $34 / 34(100)$ & $77 / 80(96)$ \\
\hline \multicolumn{4}{|l|}{ Interface } \\
\hline $\begin{array}{l}\text { The NIRS module was } \\
\text { stable and did not } \\
\text { crash }^{\mathrm{b}}, \mathrm{n} / \mathrm{N}(\%)\end{array}$ & $34 / 45(76)$ & 23/35 (66) & $57 / 80(71)$ \\
\hline \multicolumn{4}{|l|}{ Preparation for using NIRS } \\
\hline $\begin{array}{l}\text { Relevant to prepare for } \\
\text { using the NIRS device }\end{array}$ & $41 / 45(91)$ & $31 / 35(89)$ & $72 / 80(90)$ \\
\hline
\end{tabular}

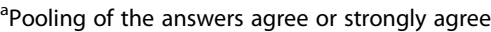

${ }^{\mathrm{b}}$ Yes to the statement

${ }^{c}$ Number of responders answering the specific question and the total number of overall responders completing the online survey

\section{Quiz}

Seventy-five of 81 (93\%) responders agreed or strongly agreed that the academic level of questions was appropriate. Of those who disagreed or strongly disagreed, no relevant difference was found between countries (Table 3) or clinical positions (Table 4). Of the six disagreeing or strongly disagreeing on the statement, five were experienced in NIRS monitoring (Table 5). Thirty-two of 81 (40\%) responders thought there were too many answer possibilities for each question, primarily nurses (20 of 40 (50\%) nurses compared to 12 of 41 (29\%) doctors) (Table 4) and Danish responders (nine of 15 (60\%) compared to seven of 16 (43\%) Spanish and 16 of 50 (32\%) Chinese responders) (Table 3). Among those with NIRS 
experience, 19 of 46 (41\%) thought there were too many answer possibilities compared to 13 of 35 (37\%) with no experience (Table 5). When asked if the quiz questions were clinically relevant and up-to-date, 77 of 80 (96\%) responders agreed or strongly agreed on this.

\section{Interface}

Almost one-third of all responders (23 of 80 (29\%)) experienced a crash once or multiple times while accessing the NIRS module. It seemed that the problem was greatest in Denmark and Spain where nine of $15(60 \%)$ and six of 15 (40\%) reported experiencing a crash, compared to only 8 of $50(16 \%)$ in China (Table 3). Among doctors and nurses, 12 of $41(29 \%)$ and 11 of 39 (28\%) experienced a crash, respectively (Table 4). Eleven of 45 (24\%) experienced with NIRS and 12 of 35 (34\%) non-experienced responders reported a crash (Table 5).

\section{Preparation for using NIRS}

When asked if the module was relevant to prepare staff members to use the NIRS device, 72 of 80 (90\%) agreed or strongly agreed on this (13 of 15 (87\%) Danish, 12 of 15 (80\%) Spanish and 47 of 50 (94\%) Chinese responders) (Table 3). No relevant difference was seen between clinical positions (35 of 40 (88\%) doctors and 37 of 40 nurses (93\%)) or between experience levels (41 of 45 (91\%) experienced and 31 of 35 (86\%) non-experienced) (Tables 4 and 5).

\section{Open-ended questions}

The thematic analysis resulted in four essential themes, accompanied by sub-themes (Fig. 3). The themes were 1) learning material-quiz discrepancies, 2) lack of clarity within course, 3) technical issues and 4) unsolicited positive comments. These four themes elicit key concepts that are essential throughout the data.

\section{Learning material-quiz discrepancies}

Some responders $(n=18)$ described a discrepancy between the learning material and the quiz, with several stating that the learning material was insufficient to adequately answer the questions in the quiz:

"For someone who know [s] little or nothing about the topic, the introduction material is not sufficient enough to answer the quiz questions" Doctor

One responder stated that despite being committed and working hard to gain a comprehension of the learning material, they struggled with answering the questions correctly and finishing the course:

"Put in a great effort to understand the intro material and I was surprised that I could not answer questions correctly. I did not feel that there was a connection between theory in the introduction material and questions" Nurse

A few mentioned $(n=6)$ that the learning material was too simple or not detailed enough and was lacking comprehensiveness:

\section{"Additional knowledge is needed in the principles} and concepts section" Nurse

As a possible consequence of this discrepancy, some responders $(n=10)$ also expressed that the content of the course was too hard:

"The content is too hard to understand" Nurse

"The questions are difficult, and the basic courses are few" Doctor

Some responders $(n=23)$ also stated that specific clinical content was missing in the learning material, which made it difficult to complete the quiz. A specific concern raised ( $n=14)$ was the absence of knowledge regarding the practicality behind the usage and handling of the NIRS device:

\section{"Risk of skin marks and side-effects is not described sufficiently in the introduction material" Doctor}

The lack of clinical content left a few responders $(n=4)$ feeling unequipped for answering questions in relation to this:

"No introduction to how you prepared for NIRS monitoring, so it was pure guessing-you have no idea whether you need to calibrate/shave/wash or something else (prior monitoring), if you have not been told forehand" Nurse

\section{Lack of clarity within the course}

Language issues were mentioned $(n=6)$, including that the language was not precise and clear, which made it hard to understand the context of the course. This was voiced by Spanish $(n=1)$ and Chinese $(n=5)$ participants:

"... The language is not enough concise and clear" Doctor

The transparency of the module's structure was also criticised, with a few responders $(n=7)$ stating that the feedback mechanism was hard to figure out:

"[The module] did not tell me what my wrong answers I had, and therefore I didn't know what the correct answers were and I couldn't find it in the introduction material" Nurse 


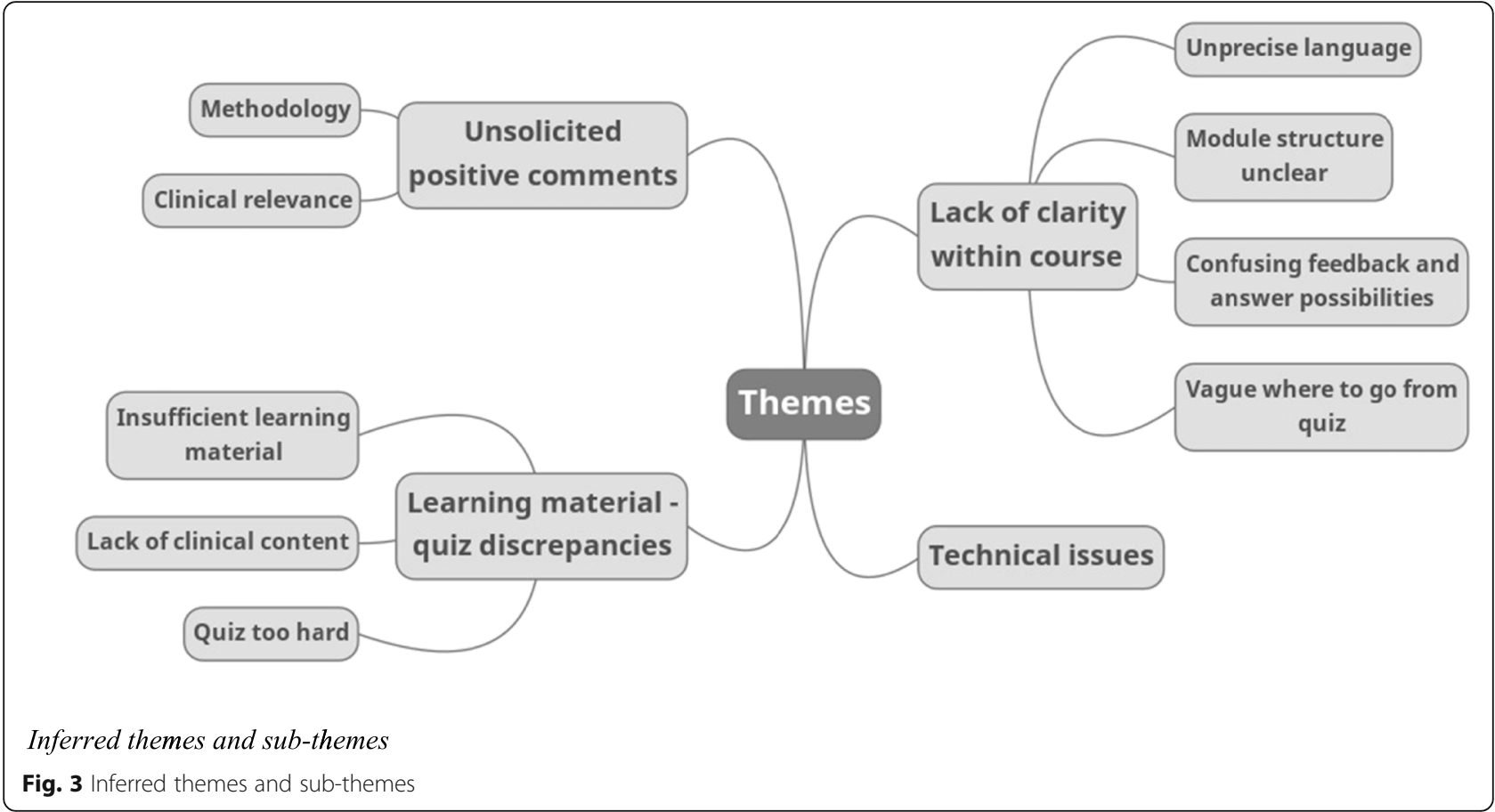

In this event, one mentioned that it was hard to learn something from answering incorrectly:

"It would be nice if one could learn something by answering wrong, hence that you could use the box that pops up after you answer incorrectly to see what was the correct answer." Nurse

In specific regards to the module lacking clarity, the deficient explanation of the quiz set-up was described. One responder expressed that it should be stated more explicitly how the module was structured:

"Very good, but I was not prepared for a casesetup-and many answer possibilities were not mentioned in the introduction material" Nurse

A few $(n=4)$ respondents stated that having multiple answer possibilities was an issue:

"I think the quality of learning is increased if there are more questions with fewer answer possibilities. The purpose is learning and I think this could be heightened if one is presented with more questions with lesser answer possibilities ... ." Doctor

\section{Technical issues}

Technical issues seemed to be a source of frustration in this course. Responders answered that the module entered into a loop of incorrect questions $(n=4)$, that it crashed $(n=8)$, that the speed was slow $(n=5)$, and that the screen froze $(n=12)$, with one responder describing how it froze three to four times in a row, which caused this person to restart and begin all over again:

"If you do it, you will be stuck, you can not finish it, what the hell" Doctor

"The page hangs on some occasions and does not allow to advance. When there is an incorrect answer, it loops in and you must restart the questionnaire to get out of there" Doctor

The accessibility also seemed to be a problem. A few $(n=4)$ experienced that they could not easily navigate between the quiz and learning material without losing answers or facing a module crash, which in some cases led to a failure to finish the quiz:

"Problems when some question is incorrect: it does not allow one to advance, in spite of reviewing the material and you must leave the page" Doctor

\section{Unsolicited positive comments}

Despite the open-ended questions being focused on clarifying any critique points of the module as well as potential improvements, some responders $(n=12)$ also commented on the positive aspects of the module. Some applauded the clinical relevancy and fitness for clinical use: 


\section{"Suitable for application of clinical" Doctor}

Others were positive towards the method of learning:

"I really like the methodology in this e-learning course ..." Doctor

Some were also generally positive such as:

"Just right, very good" Doctor

"Super topic" nurse

"Very helpful" nurse

"Relatively friendly" nurse

\section{Discussion}

This pilot study of a module on cerebral NIRS monitoring for the SafeBoosC-III web-based training and certification program shows that it is possible to complete the module within a reasonable time frame, that the academic level is appropriate and that clinical relevance is high, irrespective of previous experience, clinical position or nationality.

In order to prepare for practical use, training must include clinically relevant scenarios. In the SafeBoosC web-based training and certification program, training cases are based on real-life scenarios and written by clinically experienced neonatologists and experts in the field $[24,25,31-33]$, thereby making it possible to merge wide clinical experience and up-to-date literature within the field.

The external validity of our results is high [34] since the training module was tested in three different countries (Denmark, Spain and China), across two continents (Europe and Asia). Furthermore, we invited participants both with- and without previous experience on NIRS monitoring to participate. This was done to evaluate whether previous experience affected performance and comprehension. In SafeBoosC-III, the level of NIRS experience will vary between departments; thus, knowledge on feasibility of the certification and training program dependent on previous experience level is important. By using both closed- and open-ended questions, we were able to gain a wider and deeper understanding of the participants' experience, which revealed important strengths and limitations of our design.

Translation of the training module was done manually by AP and GC (see "Methods" section) without any external translation support. Due to limited resources, we were not able to assess the quality and precision of the translations from English to Spanish and Chinese and were therefore not able to determine whether the quality and precision of the translations affected the difference in performance parameters and satisfaction rates. Despite a reasonable participation rate with 81 of 100 participants completing the online survey, we do not know for certain if all 81 responders completed the module. When looking at performance data (time to completion and number of questions to completion), 77 of the 81 responders had entered data for at least one of these parameters. However, two of the 77 responders commented that they did not complete the module, despite entering data on performance. Thus, we do not find data entry on performance parameters reliable as a measure of module completion. If we ought to rely on comments from responders, a total of five commented that they did not complete the module, primarily due to technical issues. Furthermore, we do not know whether the 19 participants who did not answer the survey still entered the training module but, due to unknown reasons, refrained from participating in the survey. Theoretically, it is possible that some of the 19 participants have been training in the module but gave up before completion and therefore did not answer the survey. Due to restricted time, it was not possible for us to host the piloting in Moodle, which would have made it possible to track completion rates.

When looking at performance data, the ranges of estimates are wide, with an upper limit of 50 questions for 'number of questions to completion' and $420 \mathrm{~min}$ for 'time to completion' (Table 3). However, only one responder answered 50 questions, one answered 30 questions and the remaining 79 responders answered using 20 questions or less. Regarding 'time to completion', six responders reported that they spent $420 \mathrm{~min}$ in the module, but only between 20 and 8 questions. They were all from the same country. The module automatically tracks time spent in the module, and when you reach completion, it will report the total time until completion. We suspect, therefore, that the six responders have had the module open throughout a 7-hour period but only trained part of the time. The remaining 75 responders spent 60 min or less.

Despite that web-based training provides a platform to train large numbers of staff across multiple countries, it also has the disadvantage of not knowing exactly how training was conducted locally. Since we could not monitor training on-site, we do not know whether responders trained in groups instead of individually, or how much they supported each other in completing the module. This could potentially affect performance data as well as answers to the questionnaire, thereby decreasing the validity of our results. However, using the SafeBoosC web-based training and certification program for group training instead of individual training may also be the case outside this pilot study; thus, this might depict how training and certification will be conducted when it is implemented externally. The module is structured and built for individual training, but group training may encourage discussions regarding the learning topics and therefore an increased learning opportunity. 
By evaluating participants' experience only through an online survey, we have potentially missed out important information and thereby the foundation for additional improvement. A semi-structured interview [35] with randomly selected responders from each country might have given us a deeper understanding of responses. However, due to restricted time and limited budget, this was not possible to conduct.

Despite positive responses, this piloting also revealed room for improvement, as described in the "Results" section. Major critique points included 1) too many answer possibilities, 2) inadequate correlation between learning material and quiz, and 3) too many technical problems hindering completion of the module. All of these points have been taken into consideration when we revised this specific module as well as designed the additional modules for the SafeBoosC-III web-based training and certification program; at first, we revised and edited all question within the modules so that only one or two correct answer possibilities persisted, in contrast to the previous design where some questions held up to five correct answers. We also scaled the questions so that the maximum number of answer possibilities was limited to five, as opposed to previously having up to ten possibilities. This condensing of the questions required that we split some of the complex questions into two or more focused questions, thereby creating a larger pool of questions per learning objective. Secondly, for each module, we cross-checked the content of the learning material with questions in the quiz in order to identify inconsistencies. If such were found, relevant content was added to the learning material in order to ensure adequate coverage of the learning material.

Regarding the technical problems, a new IT consultant identified several errors in the coding that caused crashes and other technical difficulties. These were corrected and implemented in all the training modules.

As of today, the full-scale SafeBoosC web-based training and certification program is hosted in Moodle on a commercial platform and up-and-running. It has been translated into Chinese, Turkish, Spanish, German and French using a similar approach as was done for this pilot study. So far, more than 500 staff members have trained, and we have not yet received complaints related to any of the major critique points revealed in the pilot phase, including technical errors.

We hope that our reporting of developing and implementing web-based training for a pragmatic, multinational study will encourage other trialists to take a similar approach despite limited funding, as well as reporting on the process for the benefit of peers.

\section{Conclusion}

We believe that we provide evidence of the feasibility of developing a multilingual web-based training program for an international trial, despite challenges such as low budget, language barriers and possibly differences in the clinical training of staff. Exploring the integration of training and certification for international trials, the positive results of this study motivate further developments.

\section{Abbreviations}

GCP: Good Clinical Practice; NIRS: Near-infrared spectroscopy; SafeBoosC: Safeguarding the brains of our smallest children; USD: United States dollars

\section{Acknowledgements}

We sincerely thank all doctors and nurses from participating neonatal intensive care units who took their time to complete the web-based training module on NIRS as well as answered our online survey. We also thank Simon Hyttel-Sørensen (Department of Neonatology, Rigshospitalet, Denmark) for writing content for the module on NIRS monitoring.

\section{Resources}

Since funding is limited, the neonatologists agreed on writing the content for the training modules free of charge. They are academic partners of the SafeBoosC project. Writing content for all five modules took approximately 100 h. Expenses to Copenhagen University Hospital e-learning section was 19,000 USD and covered consultancy on pedagogic methodology as well as programming. Furthermore, we outsourced the tasks of reprogramming the modules in different languages through Fiverr (www.fiverr.com), an online freelance service market place, where online tech professionals can offer their services. Reprogramming one module in one new language is about 100 USD. Local translation has been estimated to approximately 4 hours per module.

\section{Authors' contributions}

MLH and MIR contributed to the development of the online training module on NIRS monitoring, contributed to the conception and design of this study, collected and analysed data, drafted the manuscript and will give final approval of the version to be published. SR contributed to the development of the online training module on NIRS monitoring, contributed to the conception and design of this study, drafted the manuscript and will give final approval of the version to be published. AP and GC translated content for the module on NIRS monitoring into Spanish and Chinese respectively, recruited participants, collected data, revised the manuscript critically for important intellectual content and will give final approval of the version to be published. XX and $Y Z$ recruited participants, collected data, revised the manuscript critically for important intellectual content and will give final approval of the version to be published. VZ contributed to the conception and design of this study, drafted the manuscript and will give final approval of the version to be published. GG contributed to the development of the online training module on NIRS monitoring, contributed to the conception and design of this study, drafted the manuscript and will give final approval of the version to be published.

\section{Funding}

The sponsor/coordinating investigator, Professor of Neonatology Gorm Greisen is the initiator of the SafeBoosC-III project. He has no financial interest in the results of the trial, nor in the NIRS devices. The Elsass Foundation, Aage and Johanne Louis-Hansen Foundation and Svend Andersen Foundation supported this work through unconditional and unrestricted grants of DKK 2,700,000, DKK $1,000,000$ and DKK 1,000,000, respectively. These funding sources had no role in the design of this study and will not have any role during its execution, analysis, interpretation of the data or decision to submit results.

\section{Availability of data and materials}

The datasets used and/or analysed during the current study are available from the corresponding author on reasonable request.

\section{Ethics approval and consent to participate}

According to Danish, Chinese and Spanish laws, survey studies are not considered biomedical research and ethics approval is not therefore required to conduct this study. No personal data were collected on the participants, except for the self-reported data on clinical position and nationality. Prior to study initiation, participants were informed about this. 


\section{Consent for publication}

Not applicable.

\section{Competing interests}

The authors declare that they have no competing interests.

\section{Author details}

'Department of Neonatology, Rigshospitalet, Blegdamsvej 9, 2100 Copenhagen, Denmark. ${ }^{2}$ Section for Learning Technology, Center for HR, Kildegårdsvej 28, 2900 Hellerup, Capital Region of Denmark, Denmark. ${ }^{3}$ Department of Neonatology, La Paz University Hospital, Paseo de La Castellana 261, 28046 Madrid, Spain. ${ }^{4}$ Department of Neonatology, Children's Hospital of Fudan University, 399 Wanyuan Rd, Minhang Qu, Shanghai Shi, China. ${ }^{5}$ Department of Neonatology, Key laboratory of Neonatal Diseases, Xiamen Children's Hospital, 10 Zhenhai Road, Xiamen, Fujian province, China. ${ }^{6}$ Department of Neonatology, Dehong People's Hospital of Yunnan Province, 13 Yong Han Street, Dehong Mangshi City, Yunnan province, China. ${ }^{7}$ Copenhagen University the department of Public Health, Section for Health Services Research, Rigshospitalet, JMC, Department of Women's and Children's Health, Tagensvej 22, 2200 Copenhagen, Denmark.

Received: 3 October 2019 Accepted: 25 February 2020

Published online: 23 April 2020

\section{References}

1. Garattini S, Jakobsen JC, Wetterslev J, Bertelé V, Banzi R, Rath A, et al. Evidence-based clinical practice: Overview of threats to the validity of evidence and how to minimise them. Eur J Intern Med. 2016;32:13-21.

2. Nardini C. The ethics of clinical trials. Ecancermedicalscience. 2014;8:1-9.

3. CHMP. Guideline for good clinical practice E6(R2) by the International Conference on Harmonisation of Technical Requirements for Registration of Pharmaceuticals for Human Use. Eur Med Agency. 2016;6:1-70.

4. Walker R, Morris DW, Greer TL, Trivedi MH. Research staff training in a multisite randomized clinical trial: Methods and recommendations from the stimulant reduction intervention using dosed exercise (STRIDE) trial. Addict Res Theory. 2014:22:407-15.

5. Targum SD. Evaluating rater competency for CNS clinical trials. J Clin Psychopharmacol. 2006;26:308-10.

6. Mulsant BH, Kastango KB, Rosen J, Stone RA, Mazumdar S, Pollock BG. Interrater reliability in clinical trials of depressive disorders. Am J Psychiatry. 2002;159:1598-600.

7. Clark RC, Mayer RE. E-learning and the science of instruction: Proven guidelines for consumers and designers of multimedialearning. 3rd ed. San Francisco: Wiley; 2011.

8. Ruiz JG, Mintzer MJ, Leipzig RM. The impact of e-learning in medical education. Acad Med. 2006;81:207-12.

9. Palmer RC, Samson R, Triantis M, Mullan ID. Development and evaluation of a web-based breast cancer cultural competency course for primary healthcare providers. BMC Med Educ. 2011;11:59.

10. Brown M, Bullock A. Evaluating PLATO: postgraduate teaching and learning online. Clin Teach. 2014;11:10-4.

11. Antonoff MB, Verrier ED, Allen MS, Aloia L, Baker C, Fann Jl, et al. Impact of Moodle-based online curriculum on thoracic surgery in-training examination scores. Ann Thorac Surg. 2016;102:1381-6.

12. Thukral A, Sasi A, Chawla D, Datta P, Wahid S, Rao S, et al. Online Neonatal Training and Orientation Programme in India (ONTOP-IN)--the way forward for distance education in developing countries. J Trop Pediatr. 2012;58:48690.

13. Pelayo-Alvarez M, Perez-Hoyos S, Agra-Varela Y. Clinical effectiveness of online training in palliative care of primary care physicians. J Palliat Med. 2013;16:1188-96.

14. Oliveira AC, Mattos S, Coimbra M. Development and assessment of an elearning course on pediatric cardiology basics. JMIR Med Educ. 2017;3:e10.

15. Frehywot S, Vovides $\mathrm{Y}$, Talib Z, Mikhail N, Ross H, Wohltjen H, et al. Elearning in medical education in resource constrained low- and middleincome countries. Hum Resour Health. 2013;11:4.

16. Vaona A, Banzi R, Kwag KH, Rigon G, Cereda D, Pecoraro V, et al. E-learning for health professionals. Cochrane Database Syst Rev. 2018;5:12.

17. Cook DE, Levinson AJ, Garside S, Dupras DM, Erwin PJ, Montori VM. Internet-based learning in the health professions. JAMA. 2014;300:1181-96.
18. Cook DA. Web-based learning: pros, cons and controversies. Clin Med (Northfield II). 2007;7:37-42.

19. Benjamin SE, Tate DF, Bangdiwala SI, Neelon BH, Ammerman AS, Dodds JM, et al. Preparing child care health consultants to address childhood overweight: A randomized controlled trial comparing web to in-person training. Matern Child Health J. 2008;12:662-9.

20. Ford I, Norrie J. Pragmatic trials. N Engl J Med. 2016;375:454-63.

21. Bloom BS, Krathwohl DR, Masia BS. Taxonomy of educational objectives, the classification of educational goals : Cognitive domain handbook 1. New York: Longman; 1984.

22. Wojcikowski K, Kirk L. Immediate detailed feedback to test-enhanced learning: An effective online educational tool. Med Teach. 2013;35:915-9.

23. Reis LO, Ikari O, Taha-Neto KA, Gugliotta A, Denardi F. Delivery of a urology online course using moodle versus didactic lectures methods. Int I Med Inform. 2015:84:149-54.

24. Hyttel-Sørensen S, Pellicer A, Alderliesten T, Austin T, Van Bel F, Benders M, et al. Cerebral near infrared spectroscopy oximetry in extremely preterm infants: phase II randomised clinical trial. BMJ. 2015;350:1-11.

25. Greisen G, Andresen B, Plomgaard AM, Hyttel-Sørensen S. Cerebral oximetry in preterm infants: an agenda for research with a clear clinical goal. Neurophotonics. 2016;3:31407.

26. Hyttel-Sorensen S, Kleiser S, Wolf M, Greisen G. Calibration of a prototype NIRS oximeter against two commercial devices on a blood-lipid phantom. Biomed Opt Express. 2013;4:1662-72.

27. Hyttel-Sørensen S, Greisen G, Als-Nielsen B, Gluud C. Cerebral near-infrared spectroscopy monitoring for prevention of brain injury in very preterm infants. Cochrane Database Syst Rev. 2017;9:CD011506.

28. Hyttel-Sorensen S, Hessel TW, la Cour A, Greisen G. A comparison between two NIRS oximeters (INVOS, OxyPrem) using measurement on the arm of adults and head of infants after caesarean section. Biomed Opt Express. 2014;5:3671.

29. Wang Y-S. Assessment of learner satisfaction with asynchronous electronic learning systems. Inf Manag. 2003;41:75-86.

30. Braun V, Clarke V. Using thematic analysis in psychology. Qual Res Psychol. 2006:3:77-101.

31. Pellicer A, Greisen G, Benders M, Claris O, Dempsey E, Fumagally M, et al. The SafeBoosC phase II randomised clinical trial: A treatment guideline for targeted near-infrared-derived cerebral tissue oxygenation versus standard treatment in extremely preterm infants. Neonatology. 2013;104:171-8.

32. Plomgaard AM, Hagmann C, Alderliesten T, Austin T, Van Bel F, Claris O, et al. Brain injury in the international multicenter randomized SafeBoos $C$ phase II feasibility trial: Cranial ultrasound and magnetic resonance imaging assessments. Pediatr Res. 2016;79:466-72.

33. Riera J, Hyttel-Sorensen S, Bravo MC, Cabañas F, López-Ortego P, Sanchez L, et al. The SafeBoosC phase II clinical trial: an analysis of the interventions related with the oximeter readings. Arch Dis Child Fetal Neonatal Ed. 2016; 101:F333-8

34. Rothwell PM. External validity of randomised controlled trials: "To whom do the results of this trial apply?". Lancet. 2005;365:82-93.

35. Tong A, Sainsbury P, Craig J. Consolidated criteria for reporting qualitative research (COREQ): a 32-item checklist for interviews and focus groups. Int J Qual Health Care. 2007;19:349-57.

\section{Publisher's Note}

Springer Nature remains neutral with regard to jurisdictional claims in published maps and institutional affiliations.

Ready to submit your research? Choose BMC and benefit from:

- fast, convenient online submission

- thorough peer review by experienced researchers in your field

- rapid publication on acceptance

- support for research data, including large and complex data types

- gold Open Access which fosters wider collaboration and increased citations

- maximum visibility for your research: over $100 \mathrm{M}$ website views per year

At BMC, research is always in progress.

Learn more biomedcentral.com/submissions 